\title{
Strongyloidiasis: is it transmitted from husband to wife?
}

\author{
DAVID I GROVE \\ From the Department of Medicine, University of Western Australia, Queen Elizabeth II Medical Centre, \\ Nedlands, Western Australia
}

SUMMARY The possible transmission of Strongyloides stercoralis from men who had been infected for many years to their wives was investigated. None of the 24 wives was infected, as indicated by the absence of anti-Strongyloides antibodies in their serum. Thus, the risk of transmission from husband to wife seems small, although the likelihood among homosexuals is greater.

\section{Introduction}

The sexual transmission of enteric parasites has attracted continuing attention since Mylius and ten Seldam $^{1}$ in 1962 described a married couple in whom both partners had contracted genital amoebiasis. Protozoal infections are more common than helminth infections, and transmission occurs more frequently, but not exclusively, in homosexual patients. $^{2-4}$

The purpose of this investigation was to determine whether the human helminthic parasite, Strongyloides stercoralis, could be transmitted from husband to wife.

\section{Patients and methods}

Twenty-four couples, of whom the wife did not live in an endemic area but the husband had been infected continuously for at least 35 years since being a prisoner-of-war in South-east Asia, were studied. The parasitological and clinical features of the men have been described earlier. ${ }^{5}$ The couples had been married for many years (range 22-45, mean 35, median 35 years).

Sera were obtained from all 24 couples. The diagnosis of strongyloidiasis was made by a sensitive and specific immunofluorescent antibody assay, in which an anti-Strongyloides antibody titre of $>1 / 4$ was indicative of infection. ${ }^{6}$

Address for reprints: Dr D I Grove, Department of Medicine, Medical School Building, Queen Elizabeth II Medical Centre, Nedlands, Western Australia 6009

Accepted for publication 3 March 1982

\section{Results}

All 24 men had serum antibodies with titres ranging from $1 / 8$ to $1 / 512$. No antibodies were detected in 23 wives while one had a titre of $1 / 2$.

\section{Discussion}

Many of the men with strongyloidiasis were concerned to know whether the infection could have been communicated to members of their families, particularly their wives. There have been suggestions that various helminths may be sexually transmitted; these include Enterobius vermicularis, ${ }^{7}$ Hymenolepis nan $a,{ }^{2}$ and $S$ stercoralis. ${ }^{8}$

$S$ stercoralis, however, is a most unusual helminth as it has the capacity to replicate within the same host. This is achieved by the maturation of some non-infective rhabditiform larvae into infective filariform larvae within the intestinal contents. These larvae then either penetrate the intestinal mucosa (internal autoinfection) or the perianal skin (external autoinfection). Consequently, this worm resembles other classes of micro-organisms, such as bacteria or protozoa, in its potential ability to infect other individuals directly without the participation of an intermediate host or the need for a period of development in the external environment.

There are several theoretical means by which infection can be transmitted. A person could be infected by contact with larvae in faeces which had soiled the perianal skin of the partner. Infection could also be acquired during handling and washing of clothes which had been contaminated with faeces. Despite the probability of numerous opportunities for such exposure, none of the women in this study had become infected. 
Thus there seems to be little risk of transmission of strongyloidiasis in normal family surroundings. In view of the life cycle of this parasite, however, the likelihood of transmission among homosexuals would probably be much greater, particularly if the passive partner is infected. Further studies are needed to clarify this point.

The technical assistance of Miss C Maizey is gratefully acknowledged.

\section{References}

1. Mylius RE, ten Seldam REJ. Venereal infection by Entamoeba histolytica in a New Guinea native couple. Trop Geog Med $1962 ; 14: 20-6$.

2. Harris JRW. Sexually transmitted protozoa and helminths. In Morton RS, Harris JRW, eds. Recent Advances in Sexually Transmitted Diseases. Edinburgh: Churchill Livingstone 1975:365-6.
3. Felman YM Ricciardi NB Sexually transmitted enteric diseases. Bull NY Acad Med 1979;55:533-9.

4. Anonymous. Sexual transmission of enteric pathogens. Lancet 1981;ii: 1328-9.

5. Grove DI. Strongyloidiasis in allied ex-prisoners of war in South-east Asia. Br Med J 1980; 280:598-601.

6. Grove DI, Blair AJ. Diagnosis of human strongyloidiasis by immunofluorescence using $S$ ratti and $S$ stercoralis larvae. Am J Trop Med Hyg 1981;30:344-9.

7. Waugh MA. Threadworm infestation in homosexuals. Transactions of the St John Hospital Dermatological Society 1972 58:224-5.

8. Phillips SC, Mildvan D, William DC, Gelb AM, White MC. Sexual transmission of enteric protozoa and helminths in venereal disease clinic population. $N$ Engl J Med 1981; 305:604-6. 